\title{
Association of CFTR gene polymorphisms with papillary thyroid cancer
}

\author{
IN-HWAN OH ${ }^{1}, \mathrm{CHANGMO} \mathrm{OH}^{1}$, TAI-YOUNG YOON ${ }^{1}$, JOONG-MYUNG CHOI ${ }^{1}$, SU KANG KIM ${ }^{2}$, \\ HAE JEONG PARK ${ }^{2}$, YOUNG GYU EUN ${ }^{3}$, DAE HAN CHUNG ${ }^{4}$, KEE HWAN KWON ${ }^{4}$ and BONG-KEUN CHOE ${ }^{1}$ \\ ${ }^{1}$ Department of Preventive Medicine; ${ }^{2}$ Kohwang Medical Research Institute, School of Medicine, \\ Kyung Hee University, Seoul 130-701; ${ }^{3}$ Department of Otolaryngology-Head and Neck Surgery, \\ Changwon Samsung Hospital, Sungkyunkwan University, School of Medicine, Changwon 630-723; \\ ${ }^{4}$ Department of Otolaryngology-Head and Neck Surgery, School of Medicine, \\ Kyung Hee University, Seoul 130-701, Republic of Korea
}

Received August 1, 2011; Accepted October 31, 2011

DOI: $10.3892 / \mathrm{ol} .2011 .479$

\begin{abstract}
The incidence of thyroid cancer has been on the increase in a number of countries, and certain genetic factors associated with the increased incidence of the papillary thyroid cancer (PTC) have been identified. However, little is known about the effect of mutations of the cystic fibrosis transmembrane conductance regulator (CFTR) gene, expressed in the thyroid. We hypothesized and investigated that CFTR single nucleotide polymorphisms (SNPs) may be associated with the risk and/or progression of PTC. A total of 105 PTC patients, confirmed by pathological tests, and 323 controls, without any thyroidal disease, were recruited. One promoter SNP (rs4148682) and one coding SNP (rs213950, Val470Met) in the CFTR gene were analyzed, using direct sequencing. The PTC patients were sub-grouped and compared by their clinical and pathological characteristics of PTC. The results showed that the association between SNPs in the CFTR gene and the development of PTC was statistically insignificant. However, in the clinical and pathological features, rs4148682 was found to be correlated with multifocal tumors, location and cervical node metastasis of PTC. rs231950 was also correlated with multifocal tumors, location and nodal metastasis of PTC. The $\mathrm{G}$ allele of rs 213950 was correlated with increased risk of multifocal tumors and bilateral lobe location. However, in cervical lymph node metastasis, the A allele of rs213950 was found to reflect high risk. Our study suggests that the CFTR gene polymorphisms studied may not be associated with the development of PTC, but that rs4148682 and rs213950 may be associated with clinical features and prognosis, such as multi-
\end{abstract}

Correspondence to: Professor Bong-Keun Choe, Department of Preventive Medicine, School of Medicine, Kyung Hee University, 1 Hoegi Dong, Dongdaemun Gu, Seoul 130-701, Republic of Korea E-mail:pmkhu@paran.com

Key words: papillary thyroid cancer, cystic fibrosis transmembrane conductance regulator gene, polymorphism focality, location of cancer and cervical lymph node metastasis of PTC.

\section{Introduction}

Thyroid cancer originates from either follicular or nonfollicular thyroid cells (1). Follicular cancers represent the majority of cases of thyroid cancer, and are divided into papillary thyroid cancer (PTC), follicular thyroid cancer (FTC), Hürthle cell cancer (HCC) and anaplastic thyroid cancer (ATC). Among them, PTC accounts for the majority of cases recorded (1). Thyroid cancer is the most common endocrine neoplasm in the United States (1) and its incidence is on the increase, although most of this increase is attributed to a growth in detection rates (2). In Korea, the situation is similar to that of the United States. In 2007, thyroid cancer became the most common type of cancer in females (73.5 individuals per 100,000) (3). Improvements in diagnostic techniques are regarded as the main reason for this sharp increase. Similarly, PTC accounts for the majority of increased incidence $(2,4)$.

Due to its high incidence, numerous efforts have been made to elucidate the cause of PTC. Previous studies suggested the role of genetic factors (5). In PTC, many genetic mutations have been correlated with the mitogen-activated protein kinase (MAPK) signaling pathway (5).

The cystic fibrosis transmembrane conductance regulator (CFTR) gene encodes the protein acting as the $\mathrm{Cl}^{-}$channel and as a regulator of other transporters (6). The mutation of this gene results in cystic fibrosis, which is an autosomal recessive disorder (7). Cystic fibrosis affects the epithelial tissue of various organ systems, including the respiratory, gastrointestinal and urogenital system (8). Cystic fibrosis is also associated with subclinical hypothyroidism and the expression of CFTR in the thyroid $(6,9)$. In addition, studies have suggested the presence of CFTR-dependent iodine fluxes (6). A cohort study of cystic fibrosis revealed an increased risk of thyroid cancer in cystic fibrosis patients in addition to lymphoma and kidney neoplasms (10).

Thus, CFTR expression may be associated with the risk and/or progression of PTC. In this study, we investigated the 
genetic association between $C F T R$ single nucleotide polymorphisms (SNPs) and PTC in a Korean population.

\section{Patients and methods}

Patients. In the present study, normal controls $(\mathrm{n}=323$, 134 males and 189 females) and PTC patients ( $\mathrm{n}=105,30$ males and 75 females) were analyzed. The PTC patients were enrolled, with their agreement, from the patients who visited Kyung Hee University Medical Center, Seoul, Republic of Korea, between October 2007 and December 2010. The control group was recruited from healthy individuals, without any thyroidal disease, who visited the same institution for health examinations. The diagnosis of PTC and nodal metastasis was confirmed by pathological examination. The average age of the studied groups was 55.7 in the patient group and 56.5 in the control group. Written informed consent was obtained from all subjects. The study was approved by the Ethics Review Committee of the Medical Research Institute, Kyung Hee University Medical Center, Seoul, Republic of Korea.

Subgroups of patients. Patients were subgrouped by size, focality, location, extranodal, cervical lymph node and angiolymphatic invasion of cancer to investigate the possible association between clinical characteristics and SNPs of CFTR . Of the 105 PTC patients, the size of cancer was $\geq 1 \mathrm{~cm}$ in 54 patients, whereas 65 patients were found to have unifocality, but 36 patients showed multifocality. In addition, in 65 patients, the location of cancer was limited to one lobe, whereas in 36 patients, cancer was found in both lobes. Extranodal invasion waws detected in 53 patients, 29 had cervical lymph node invasion and 5 patients were diagnosed with angiolymphatic invasion (Table I).

SNP selection and genotyping. We searched for the promoter and coding SNPs of the CFTR gene. The search was conducted using the SNP database of the National Center for Biotechnology Information (http://www.ncbi.nlm.nih.gov/ SNP, BUILD 132). SNPs were selected from the promoter regions within $-1000 \mathrm{bp}$ from the transcriptional start sites and coding region. The SNPs with unknown heterozygosity, with a heterozygosity $\leq 0.1$ or with a minor allele frequency $\leq 0.1$ in the Han Chinese and Japanese populations were excluded from the analysis. Two SNPs (rs4148682, promoter; rs213950, missense, Val470Met) were selected. DNA was isolated from peripheral blood samples, using the DNA isolation kit for blood (Roche, Indianapolis, IN, USA). Genotyping of the CFTR polymorphism was performed by direct sequencing. Polymerase chain reactions (PCRs) were performed using primers for rs4148682 (promoter) and rs213950 (missense) (Table II). The ABI PRISM 3730XL analyzer (PE Applied Biosystems, Foster City, CA, USA) was used to sequence the PCR products and SeqManII software (DNASTAR, Madison, WI, USA) was used to analyze the sequence.

Statistical analysis. For the two selected SNPs, Hardy-Weinberg equilibrium (HWE) was analyzed using the SNP Stats software (http://bioinfo.iconcologia.net/index.php?module=Snpstats) in both PTC patients and controls, and adjusted for gender and age. In addition, Helixtree (Golden Helix Inc., Bozeman, MT,
Table I. Clinical characteristics of the study population.

\begin{tabular}{|c|c|c|}
\hline & $\begin{array}{l}\text { PTC } \\
n=105\end{array}$ & $\begin{array}{l}\text { Control } \\
n=323\end{array}$ \\
\hline Age $($ mean $\pm \mathrm{SD})$ & $55.7 \pm 12.0$ & $56.5 \pm 10.2$ \\
\hline Gender (male/female, $n$ ) & $30 / 75$ & $134 / 189$ \\
\hline \multicolumn{3}{|l|}{ Cancer size (n) } \\
\hline$\geq 1 \mathrm{~cm}$ & 54 & \\
\hline$<1 \mathrm{~cm}$ & 49 & \\
\hline \multicolumn{3}{|l|}{ Number of tumors (n) } \\
\hline Unifocality & 65 & \\
\hline Multifocality & 36 & \\
\hline \multicolumn{3}{|l|}{ Location of cancer (n) } \\
\hline One lobe & 65 & \\
\hline Both lobes & 36 & \\
\hline \multicolumn{3}{|l|}{$\begin{array}{l}\text { Extra thyroidal } \\
\text { invasion }(n)\end{array}$} \\
\hline Absent & 49 & \\
\hline Present & 53 & \\
\hline \multicolumn{3}{|l|}{$\begin{array}{l}\text { Cervical lymph node } \\
\text { metastasis (n) }\end{array}$} \\
\hline Absent & 69 & \\
\hline Present & 29 & \\
\hline \multicolumn{3}{|l|}{$\begin{array}{l}\text { Angiolymphatic } \\
\text { invasion }(n)\end{array}$} \\
\hline Absent & 95 & \\
\hline Present & 5 & \\
\hline
\end{tabular}

PTC, papillary thyroid cancer; n, number of subjects; SD, standard deviation. PTC patients with inappropriate clinical data were excluded.

USA), SNP Analyzer (ISTECH Inc., Goyang, Republic of Korea) and SPSS (SPSS Inc., Chicago, IL, USA) were used to analyze the genetic data. Linkage disequilibrium (LD) analysis was conducted using Haploview version 4.2 (Broad Institute, Cambridge, MA, USA), and Gabriel's methods were used to construct the LD block (11). Multiple logistic regression models were used to reflect the co-dominant, dominant and recessive models. The odds ratio (OR), 95\% confidence intervals (CIs) and P-value were calculated, controlling gender and age as covariates. $\mathrm{P}<0.05$ was considered to be statistically significant.

\section{Results}

Table III shows the distribution of the genotypes and allele of CFTR SNPs in the study group. In addition, the multiple logistic regression model, adjusting for age and gender, was used to investigate the possible association with PTC. Various models were applied in the multiple logistic regression analysis (co-dominant 1, major allele homozygotes and heterozygotes; co-dominant 2, major allele homozygotes and minor allele homozygotes; dominant, major allele homozygotes and heterozygotes + minor allele homozygotes; recessive, major allele homozygotes + heterozygotes and minor allele homo- 
Table II. Primer sequences for each SNP.

\begin{tabular}{lll}
\hline SNP & \multicolumn{1}{c}{ Forward } & Reverse \\
\hline rs4148682 & GACACAGGCAATCCTACACAAA & GGTGGCACAGAAATCTTAGGAC \\
rs213950 & CCCTTGTATCTTTTGTGCATAG & TGCTTTGATGACGCTTCTGTAT \\
\hline
\end{tabular}

SNP, single nucleotide polymorphism.

Table III. Genotype and allele frequencies of the CFTR gene in the study population.

\begin{tabular}{|c|c|c|c|c|c|c|c|}
\hline \multirow[t]{2}{*}{ SNP } & & \multirow[t]{2}{*}{ Type } & \multirow{2}{*}{$\frac{\text { Control }}{\mathrm{n}(\%)}$} & PTC & \multirow[t]{2}{*}{ Model } & \multirow[t]{2}{*}{ OR $(95 \%$ CI) } & \multirow[t]{2}{*}{ P-value } \\
\hline & & & & $\mathrm{n}(\%)$ & & & \\
\hline \multirow{6}{*}{$\begin{array}{l}\text { rs4148682 } \\
-175\end{array}$} & \multirow[t]{4}{*}{ Genotype } & $\mathrm{T} / \mathrm{T}$ & $93(28.8)$ & $27(25.7)$ & Co-dominant 1 & $1.26(0.73-2.18)$ & 0.70 \\
\hline & & $\mathrm{T} / \mathrm{G}$ & $155(48)$ & $50(47.6)$ & Co-dominant 2 & $1.36(0.73-2.54)$ & 0.42 \\
\hline & & $\mathrm{G} / \mathrm{G}$ & $75(23.2)$ & $28(26.7)$ & Dominant & $1.30(0.78-2.16)$ & 0.32 \\
\hline & & & & & Recessive & $1.18(0.70-1.97)$ & 0.54 \\
\hline & \multirow[t]{2}{*}{ Allele } & $\mathrm{T}$ & $341(52.8)$ & $104(49.5)$ & & 1 & \\
\hline & & G & $305(47.2)$ & $106(50.5)$ & & $1.14(0.84-1.56)$ & 0.41 \\
\hline rs213950 & \multirow[t]{4}{*}{ Genotype } & $\mathrm{G} / \mathrm{G}$ & $110(34.1)$ & $31(29.5)$ & Co-dominant 1 & $1.23(0.73-2.07)$ & 0.64 \\
\hline \multirow[t]{5}{*}{ Val470Met } & & $\mathrm{A} / \mathrm{G}$ & $154(47.7)$ & $49(46.7)$ & Co-dominant 2 & $1.54(0.82-2.89)$ & 0.19 \\
\hline & & $\mathrm{A} / \mathrm{A}$ & $59(18.3)$ & $25(23.8)$ & Dominant & $1.32(0.81-2.14)$ & 0.27 \\
\hline & & & & & Recessive & $1.36(0.79-2.35)$ & 0.27 \\
\hline & \multirow[t]{2}{*}{ Allele } & G & $374(83.9)$ & $111(52.9)$ & & 1 & \\
\hline & & A & $272(16.1)$ & $99(47.1)$ & & $1.23(0.90-1.68)$ & 0.20 \\
\hline
\end{tabular}

PTC, papillary thyroid cancer; SNP, single nucleotide polymorphism; OR, odds ratio; CI, confidence interval. P-values were calculated from the logistic regression analyses adjusting for gender and age.

zygotes). We found that none of the SNPs [i.e., the promoter SNP (rs4148682) and the missense SNP (rs213950)] were associated with PTC. When the minor allele was used as a risk factor, no association was observed.

The association between the CFTR SNPs and the clinical characteristics of PTC are analyzed in Tables IV-VIII. We did not analyze the angiolymphatic invasion of PTC using multiple logistic regression due to the small number of angiolymphatic invasion cases $(n=5)$. In Table IV, the CFTR SNPs were not associated with cancer size. In addition, the extranodal invasion was not associated with either genotypes or allele frequencies (Table VIII). However, the focality, location and cervical node invasion of PTC were all associated with SNPs (Tables V-VII).

Therefore, rs4148682 was associated with the risk of multifocality in PTC patients [co-dominant model 1 (T/T vs. T/G), $\mathrm{OR}=0.21,95 \% \mathrm{CI}=0.08-0.60$; dominant model $(\mathrm{T} / \mathrm{T}$ and $\mathrm{T} / \mathrm{G}$ vs. $\mathrm{G} / \mathrm{G}) \mathrm{OR}=0.26,95 \% \mathrm{CI}=0.10-0.65]$. In addition, the $\mathrm{T}$ allele positively correlated with the risk of multifocality $(\mathrm{OR}=1.92$, 95\% CI=1.07-3.43). Furthermore, rs213950 (missense SNP) was found to correlate with the risk of multifocality, by the logistic regression analysis. The genotypes of rs 213950 decreased the risk of multifocality in the co-dominant 2 model (G/G vs. A/G, p=0.002) and the dominant model $(\mathrm{G} / \mathrm{G}$ and
$\mathrm{A} / \mathrm{G}$ vs. $\mathrm{A} / \mathrm{A}, \mathrm{p}=0.002)$. In addition, the $\mathrm{G}$ allele of $\mathrm{rs} 213950$ correlated with an increased risk of multifocality $(\mathrm{OR}=2.00$, 95\% CI=1.01-3.62) (Table V). In Table VI, the genotype and allele frequencies of SNPs were analyzed by location of the cancer. rs4148682 (dominant model, $\mathrm{p}=0.049$ ) and rs213950 (co-dominant 1 model, $\mathrm{p}=0.048$; dominant model, $\mathrm{p}=0.026$ ) correlated with the risk of bilateral lobe incidence. The $\mathrm{G}$ allele of $\mathrm{rs} 213950(\mathrm{OR}=1.83,95 \% \mathrm{CI}=1.02-3.29)$ was also found to increase the risk of bilateral lobe thyroid cancer.

In addition, the risk of cervical lymph node invasion was associated with SNPs of CFTR. Rs4148682 was associated with an increased risk of cervical lymph node invasion of PTC in the co-dominant 2 model $(\mathrm{p}=0.024)$ and the dominant model $(\mathrm{p}=0.023)$. Similar to rs4148682, rs213950 showed an association with the risk of cervical node invasion (co-dominant 2 model, $\mathrm{p}=0.028$; dominant model, $\mathrm{p}=0.044)$.

However, the $\mathrm{G}$ allele, rather than the $\mathrm{T}$ allele, increased the risk of cervical lymph node invasion of PTC $(\mathrm{OR}=2.13$, 95\% $\mathrm{CI}=1.14-3.99)$. In addition, the A allele of rs213950 was associated with an increased risk of cervical lymph node invasion in PTC patients (OR=2.07, 95\% CI=1.11-3.87).

Genotype distributions of the two SNPs analyzed, other than for the distribution of rs213950 with multifocality, were in HWE (P>0.05, data not shown). In the case of $\mathrm{rs} 213950$ 
Table IV. Genotype and allele frequencies of SNPs of the CFTR gene in PTC patients by size.

\begin{tabular}{|c|c|c|c|c|c|c|c|}
\hline \multirow[t]{2}{*}{ SNP } & & \multirow[t]{2}{*}{ Type } & \multirow{2}{*}{$\frac{<1 \mathrm{~cm}(\text { tumor size })}{\mathrm{n}(\%)}$} & \multirow{2}{*}{$\frac{\geq 1 \mathrm{~cm} \text { (tumor size) }}{\mathrm{n}(\%)}$} & \multirow[t]{2}{*}{ Model } & \multirow[t]{2}{*}{ OR $(95 \% \mathrm{CI})$} & \multirow[t]{2}{*}{ P-value } \\
\hline & & & & & & & \\
\hline \multirow{6}{*}{$\begin{array}{l}\text { rs4148682 } \\
-175\end{array}$} & \multirow[t]{4}{*}{ Genotype } & $\mathrm{T} / \mathrm{T}$ & $15(27.8)$ & $12(24.5)$ & Co-dominant 1 & $1.05(0.40-2.74)$ & 0.84 \\
\hline & & $\mathrm{T} / \mathrm{G}$ & $26(48.1)$ & $23(46.9)$ & Co-dominant 2 & $1.38(0.46-4.10)$ & 0.59 \\
\hline & & $\mathrm{G} / \mathrm{G}$ & $13(24.1)$ & $14(28.6)$ & Dominant & $1.16(0.47-2.83)$ & 0.75 \\
\hline & & & & & Recessive & $1.34(0.54-3.30)$ & 0.52 \\
\hline & \multirow[t]{2}{*}{ Allele } & $\mathrm{T}$ & $56(51.9)$ & $47(48.0)$ & & 1 & \\
\hline & & G & $52(48.1)$ & $51(52.0)$ & & $1.17(0.68-2.02)$ & 0.58 \\
\hline \multirow{6}{*}{$\begin{array}{l}\text { rs } 213950 \\
\text { Val470Met }\end{array}$} & \multirow[t]{4}{*}{ Genotype } & $\mathrm{G} / \mathrm{G}$ & $18(33.3)$ & $13(26.5)$ & Co-dominant 1 & $1.34(0.52-3.41)$ & 0.54 \\
\hline & & $\mathrm{A} / \mathrm{G}$ & $24(44.4)$ & $23(46.9)$ & Co-dominant 2 & $1.49(0.51-4.40)$ & 0.50 \\
\hline & & $\mathrm{A} / \mathrm{A}$ & $12(22.2)$ & $13(26.5)$ & Dominant & $1.39(0.59-3.31)$ & 0.45 \\
\hline & & & & & Recessive & $1.26(0.50-3.17)$ & 0.63 \\
\hline & \multirow{2}{*}{ Allele } & G & $60(55.6)$ & $49(50.0)$ & & 1 & \\
\hline & & A & $48(44.4)$ & $49(50.0)$ & & $1.25(0.72-2.16)$ & 0.43 \\
\hline
\end{tabular}

PTC, papillary thyroid cancer; SNP, single nucleotide polymorphism; OR, odds ratio; CI, confidence interval. P-values were calculated from the logistic regression analyses adjusting for gender and age.

Table V. Genotype and allele frequencies of SNPs of the CFTR gene in PTC patients by focality.

\begin{tabular}{|c|c|c|c|c|c|c|c|}
\hline \multirow[t]{2}{*}{ SNP } & & \multirow[t]{2}{*}{ Type } & \multirow{2}{*}{$\frac{\text { Unifocality }}{\mathrm{n}(\%)}$} & \multirow{2}{*}{$\frac{\text { Multifocality }}{\mathrm{n}(\%)}$} & \multirow[t]{2}{*}{ Model } & \multirow[t]{2}{*}{ OR $(95 \% \mathrm{CI})$} & \multirow[t]{2}{*}{ P-value } \\
\hline & & & & & & & \\
\hline rs4148682 & Genotype & $\mathrm{T} / \mathrm{T}$ & $11(16.9)$ & $16(44.4)$ & Co-dominant 1 & $0.21(0.08-0.60)$ & 0.003 \\
\hline \multirow[t]{5}{*}{-175} & & $\mathrm{~T} / \mathrm{G}$ & $36(55.4)$ & $11(30.6)$ & Co-dominant 2 & $0.34(0.11-1.04)$ & 0.06 \\
\hline & & $\mathrm{G} / \mathrm{G}$ & $18(27.7)$ & $9(25.0)$ & Dominant & $0.26(0.10-0.65)$ & 0.004 \\
\hline & & & & & Recessive & $0.84(0.33-2.15)$ & 0.72 \\
\hline & Allele & $\mathrm{G}$ & $72(55.4)$ & $29(40.3)$ & & 1 & \\
\hline & & $\mathrm{T}$ & $58(44.6)$ & $43(59.7)$ & & $1.92(1.07-3.43)$ & 0.028 \\
\hline rs213950 & Genotype & $\mathrm{G} / \mathrm{G}$ & $13(20.0)$ & $18(50.0)$ & Co-dominant 1 & $0.20(0.07-0.56)$ & 0.002 \\
\hline \multirow[t]{5}{*}{ Val470Met } & & $\mathrm{A} / \mathrm{G}$ & 35 (53.9) & $10(27.8)$ & Co-dominant 2 & $0.34(0.11-1.03)$ & 0.06 \\
\hline & & $\mathrm{A} / \mathrm{A}$ & $17(26.1)$ & $8(22.2)$ & Dominant & $0.25(0.10-0.61)$ & 0.002 \\
\hline & & & & & Recessive & $0.80(0.30-2.10)$ & 0.64 \\
\hline & Allele & A & $69(53.1)$ & $26(36.1)$ & & 1 & \\
\hline & & $\mathrm{G}$ & $61(46.9)$ & $46(63.9)$ & & $2.00(1.01-3.62)$ & 0.022 \\
\hline
\end{tabular}

PTC, papillary thyroid cancer; SNP, single nucleotide polymorphism; OR, odds ratio; CI, confidence interval. P-values were calculated from the logistic regression analyses adjusting for gender and age. Bold numbers represent a statistically significant association.

with multifocality, the P-value of the HWE test was 0.027 and showed deviation from HWE [G/G (50.0\%), A/G (27.8\%), A/A (22.2\%); A (36.1\%), G (63.9\%)].

The results of LD testing and of haplotype testing using Haploview 4.2 are shown in Fig. 1. The LD block was constructed between rs213950 and rs4148682 ( $\left.D^{\prime} \geq 0.95, r^{2} \geq 0.8\right)$ (Fig. 1).

Our findings suggest a possible association between CFTR and the clinical characteristics of PTC in a Korean population. The T allele of rs4148682 and the G allele of rs213950 were correlated with the risk of multifocality and bilateral location of the PTC. Conversely, the G allele of rs4148682 and the A allele of rs 213950 were associated with cervical lymph node metastasis.

\section{Discussion}

The aim of the present study was to evaluate the genetic association between the CFTR gene and PTC development in a Korean population. We also analyzed the relationship between the clinical characteristics of PTC and the CFTR gene. 
Table VI. Genotype and allele frequencies of SNPs of the CFTR gene in PTC patients by location.

\begin{tabular}{|c|c|c|c|c|c|c|c|}
\hline \multirow[t]{2}{*}{ SNP } & & \multirow[t]{2}{*}{ Type } & \multirow{2}{*}{$\frac{\text { One lobe }}{\mathrm{n}(\%)}$} & \multirow{2}{*}{$\frac{\text { Both lobes }}{\mathrm{n}(\%)}$} & \multirow[t]{2}{*}{ Model } & \multirow[t]{2}{*}{ OR $(95 \%$ CI $)$} & \multirow[t]{2}{*}{ P-value } \\
\hline & & & & & & & \\
\hline rs4148682 & Genotype & $\mathrm{T} / \mathrm{T}$ & $13(20.0)$ & $14(38.9)$ & Co-dominant 1 & $0.44(0.16-1.20)$ & 0.08 \\
\hline \multirow[t]{5}{*}{-175} & & $\mathrm{~T} / \mathrm{G}$ & $33(50.8)$ & $15(41.7)$ & Co-dominant 2 & $0.32(0.10-1.04)$ & 0.07 \\
\hline & & $\mathrm{G} / \mathrm{G}$ & $19(29.2)$ & $7(19.4)$ & Dominant & $0.39(0.16-1.00)$ & 0.049 \\
\hline & & & & & Recessive & $0.52(0.19-1.44)$ & 0.20 \\
\hline & Allele & G & $71(54.6)$ & $29(40.3)$ & & 1 & \\
\hline & & $\mathrm{T}$ & $59(45.4)$ & $43(59.7)$ & & $1.78(1.00-3.20)$ & 0.05 \\
\hline rs213950 & Genotype & $\mathrm{G} / \mathrm{G}$ & $15(23.1)$ & $16(44.4)$ & Co-dominant 1 & $0.37(0.14-1.00)$ & 0.048 \\
\hline \multirow[t]{5}{*}{ Val470Met } & & $\mathrm{A} / \mathrm{G}$ & $32(49.2)$ & $13(36.1)$ & Co-dominant 2 & $0.35(0.11-1.11)$ & 0.08 \\
\hline & & $\mathrm{A} / \mathrm{A}$ & $18(27.7)$ & $7(19.4)$ & Dominant & $0.36(0.15-0.89)$ & 0.026 \\
\hline & & & & & Recessive & $0.60(0.21-1.67)$ & 0.32 \\
\hline & Allele & A & $68(52.3)$ & $27(37.5)$ & & 1 & \\
\hline & & G & $62(47.7)$ & $45(62.5)$ & & $1.83(1.02-3.29)$ & 0.044 \\
\hline
\end{tabular}

PTC, papillary thyroid cancer; SNP, single nucleotide polymorphism; OR, odds ratio; CI, confidence interval. P-values were calculated from the logistic regression analyses adjusting for gender and age. Bold numbers represent a statistically significant association.

Table VII. Genotype and allele frequencies of SNPs of the CFTR gene in PTC patients by metastasis.

\begin{tabular}{|c|c|c|c|c|c|c|c|}
\hline \multirow[t]{2}{*}{ SNP } & & \multirow[t]{2}{*}{ Type } & \multirow{2}{*}{$\begin{array}{c}\begin{array}{c}\text { Cervical lymph } \\
\text { node }\end{array} \\
\text { metastasis }(-) \\
\mathrm{n}(\%)\end{array}$} & $\begin{array}{l}\text { Cervical lymph } \\
\text { node } \\
\text { metastasis }(+)\end{array}$ & \multirow[t]{2}{*}{ Model } & \multirow[t]{2}{*}{$\begin{array}{c}\text { OR } \\
(95 \% \mathrm{CI})\end{array}$} & \multirow[t]{2}{*}{ P-value } \\
\hline & & & & $\mathrm{n}(\%)$ & & & \\
\hline rs4148682 & Genotype & $\mathrm{T} / \mathrm{T}$ & $23(33.3)$ & $3(10.3)$ & Co-dominant 1 & $4.27(1.09-16.65)$ & 0.05 \\
\hline \multirow[t]{5}{*}{-175} & & $\mathrm{~T} / \mathrm{G}$ & $32(46.4)$ & $16(55.2)$ & Co-dominant 2 & $5.25(1.21-22.84)$ & 0.022 \\
\hline & & $\mathrm{G} / \mathrm{G}$ & $14(20.3)$ & $10(34.5)$ & Dominant & $4.59(1.24-17.00)$ & 0.01 \\
\hline & & & & & Recessive & $1.88(0.70-5.07)$ & 0.22 \\
\hline & Allele & $\mathrm{T}$ & $78(56.5)$ & $22(37.9)$ & & 1 & \\
\hline & & G & $60(43.5)$ & $36(62.1)$ & & $2.13(1.14-3.99)$ & 0.019 \\
\hline rs213950 & Genotype & $\mathrm{G} / \mathrm{G}$ & $25(36.2)$ & $5(17.2)$ & Co-dominant 1 & $2.36(0.74-7.59)$ & 0.18 \\
\hline \multirow[t]{5}{*}{ Val470Met } & & $\mathrm{A} / \mathrm{G}$ & $32(46.4)$ & $14(48.3)$ & Co-dominant 2 & $4.15(1.13-15.21)$ & 0.028 \\
\hline & & $\mathrm{A} / \mathrm{A}$ & $12(17.4)$ & $10(34.5)$ & Dominant & $2.88(0.96-8.62)$ & 0.044 \\
\hline & & & & & Recessive & $2.41(0.87-6.70)$ & 0.09 \\
\hline & Allele & G & $82(59.4)$ & $24(41.4)$ & & 1 & \\
\hline & & A & $56(40.6)$ & $34(58.6)$ & & $2.07(1.11-3.87)$ & 0.022 \\
\hline
\end{tabular}

PTC, papillary thyroid cancer; SNP, single nucleotide polymorphism; OR, odds ratio; CI, confidence interval. P-values were calculated from the logistic regression analyses adjusting for gender and age. Bold numbers represent a statistically significant association.

The prognosis of thyroid cancer is generally good (2); however, it is crucial to identify patients at higher risk of recurrence in order to provide appropriate monitoring and treatment. The association between various factors, such as tumor size, multifocality and clinical outcomes have been reported in patients with PTC (12). We performed analyses to identify independent correlations between the CFTR mutation status and PTC. We found no significant relationship between the CFTR gene and the development of PTC. However, the CFTR gene correlated with the clinical characteristics. Thus, the promoter SNP (rs4148682, -175T/G) and the missense SNP (rs213950, Val470Met) were associated with multifocality, bilateral location in the thyroid lobes and cervical lymph node metastasis of the PTC. Multifocality correlated with 
Table VIII. Genotype and allele frequencies of SNPs of the CFTR gene in PTC patients by invasion.

\begin{tabular}{|c|c|c|c|c|c|c|c|}
\hline \multirow[t]{2}{*}{ SNP } & & \multirow[t]{2}{*}{ Type } & \multirow{2}{*}{$\begin{array}{c}\begin{array}{c}\text { Extra-thyroidal } \\
\text { invasion }(-)\end{array} \\
\mathrm{n}(\%)\end{array}$} & \multirow{2}{*}{$\begin{array}{c}\begin{array}{c}\text { Extra-thyroidal } \\
\text { invasion }(+)\end{array} \\
\mathrm{n}(\%)\end{array}$} & \multirow[t]{2}{*}{ Model } & \multirow[t]{2}{*}{ OR $(95 \% \mathrm{CI})$} & \multirow[t]{2}{*}{ P-value } \\
\hline & & & & & & & \\
\hline \multirow{6}{*}{$\begin{array}{l}\text { rs4148682 } \\
-175\end{array}$} & Genotype & $\mathrm{T} / \mathrm{T}$ & $12(24.5)$ & $15(28.3)$ & Co-dominant 1 & $0.91(0.35-2.38)$ & 0.77 \\
\hline & & $\mathrm{T} / \mathrm{G}$ & $23(46.9)$ & $25(47.2)$ & Co-dominant 2 & $0.73(0.25-2.15)$ & 0.59 \\
\hline & & $\mathrm{G} / \mathrm{G}$ & $14(28.6)$ & $13(24.5)$ & Dominant & $0.84(0.34-2.05)$ & 0.7 \\
\hline & & & & & Recessive & $0.77(0.32-1.90)$ & 0.58 \\
\hline & Allele & G & $51(52.0)$ & $51(48.1)$ & & 1 & \\
\hline & & $\mathrm{T}$ & $47(48.0)$ & $55(51.9)$ & & $1.17(0.68-2.03)$ & 0.58 \\
\hline rs213950 & Genotype & $\mathrm{G} / \mathrm{G}$ & $14(28.6)$ & $17(32.1)$ & Co-dominant 1 & $0.83(0.33-2.10)$ & 0.68 \\
\hline \multirow{5}{*}{ Val470Met } & & $\mathrm{A} / \mathrm{G}$ & $23(46.9)$ & $23(43.4)$ & Co-dominant 2 & $0.90(0.31-2.62)$ & 0.83 \\
\hline & & $\mathrm{A} / \mathrm{A}$ & $12(24.5)$ & $13(24.5)$ & Dominant & $0.85(0.36-2.01)$ & 0.72 \\
\hline & & & & & Recessive & $1.01(0.40-2.52)$ & 0.99 \\
\hline & Allele & A & $47(48.0)$ & $49(46.2)$ & & 1 & \\
\hline & & G & $51(52.0)$ & $57(53.8)$ & & $1.07(0.62-1.86)$ & 0.80 \\
\hline
\end{tabular}

PTC, papillary thyroid cancer; SNP, single nucleotide polymorphism; OR: odds ratio; CI: confidence interval. P-values were calculated from the logistic regression analyses adjusting for gender and age.
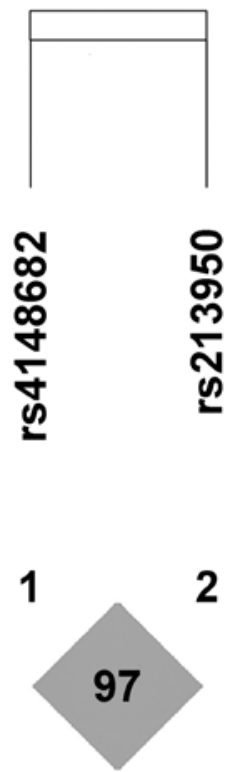

Figure 1. Linkage disequilibrium block consisting of rs4148682 and rs213950.

LN metastasis and predicted tumor recurrence in previous studies. Therefore, the significant association between the CFTR gene and clinical characteristics of PTC suggest that the genetic mutation of CFTR is capable of affecting the outcome of PTC patients $(13,14)$.

The best known mutations in PTC are the point mutation of the v-raf murine sarcoma viral oncogene homolog B1 $(B R A F)$, the rat sarcoma proto-oncogenes (RAS genes) and the rearrangement of $R E T / P T C$, which is capable of triggering the MAPK signaling pathway (5). These genetic alternations were observed in more than $70 \%$ of PTC patients. The point mutation of $B R A F$ is the most common genetic alternation and is present in approximately $45 \%$ of cases of PTC. Some of the other genetic alternations, such as the point mutation of RET/PTC 3 rearrangement and the V600E mutation of the $B R A F$ gene, suggest an aggressive phenotype and poor outcome in PTC patients $(5,12,15)$. The $B R A F$ mutation was even considered a predictor of recurrence in PTC patients with extra-thyroid invasion and lymph node metastasis (12).

A defect of the CFTR gene results in cystic fibrosis, which affects the epithelial tissue of several organs, such as the sweat duct, airway, pancreas, vas deference and intestine, although lung disease is the most significant cause of mortality in cystic fibrosis $(16,17)$. The most noteworthy feature of cystic fibrosis is the chronic bacterial infection of the airways, which results in bronchiectasis. Cystic fibrosis is also correlated with an increased risk of cancer, including thyroid cancer (10). The mutation of the CFTR gene was significantly associated with lung and pancreatic cancer in previous reports $(18,19)$. Although the increased risk of thyroid cancer $(\mathrm{OR}=9.8,95 \% \mathrm{CI}=1.2-35.5)$ may result from either frequent exposure to X-ray or from surveillance bias due to intensive follow up (10), the findings of the present study showed a possible association between genetic factors and thyroid cancer in cystic fibrosis patients.

The CFTR protein regulates various channels and transporters and the thyroid hormones stimulate the expression of the CFTR gene in the kidney (20). Subclinical hypothyroidism was observed in cystic fibrosis patients and CFTR appears to mediate the iodide ion fluxes. Therefore, the CFTR protein may affect thyroid hormone production (6). This effect may explain the association that we found between the clinical features of PTC and CFTR SNPs. To the best of our knowledge, this is the first study on the association between the CFTR gene and PTC in a Korean population. 
However, the present study has certain limitations. The number of participants was relatively small; therefore, the power of this study may be limited. The observed insignificant association between CFTR SNPs and PTC may result from the relatively small sample size. In addition, the control group was not investigated with thyroid ultrasound and possible undiagnosed PTC may therefore exist in this group. However, the incidence of thyroid cancer was 43.1 per 100,000 individuals in Korea in 2007 (3), and the possible size of misclassification is likely to be limited.

In this study, the association between the CFTR gene and PTC development, and the relationship between the clinical characteristics of PTC and CFTR were analyzed. No significant correlation was found between the CFTR gene and the development of PTC.

However, the $\mathrm{T}$ allele of rs4148682 and the $\mathrm{G}$ allele of rs213950 were correlated with the risk of multifocality and bilateral location of the cancer (i.e., in both thyroid lobes) in PTC. On the other hand, the G allele of rs4148682 and the A allele of rs213950 showed an association with cervical lymph node metastasis. This result suggested that CFTR potentially affects the clinical features and prognosis of PTC.

\section{References}

1. Brown RL, de Souza JA and Cohen EE: Thyroid cancer: burden of illness and management of disease. J Cancer 2: 193-199, 2011.

2. Davies L and Welch HG: Increasing incidence of thyroid cancer in the United States, 1973-2002. JAMA 295: 2164-2167, 2006.

3. Jung KW, Park S, Kong HJ, et al: Cancer statistics in Korea: incidence, mortality and survival in 2006-2007. J Korean Med Sci 25: 1113-1121, 2010

4. Lee JI, Kim SH, Tan AH, et al: Decreased health-related quality of life in disease-free survivors of differentiated thyroid cancer in Korea. Health Qual Life Outcomes 8: 101, 2010.

5. Nikiforov YE: Thyroid carcinoma: molecular pathways and therapeutic targets. Mod Pathol 21 (Suppl 2): S37-S43, 2008.
6. Li H, Ganta S and Fong P: Altered ion transport by thyroid epithelia from CFTR(-/-) pigs suggests mechanisms for hypothyroidism in cystic fibrosis. Exp Physiol 95: 1132-1144, 2010.

7. Gene: ENTREZ GENE. http://www.ncbi.nlm.nih.gov/sites/ entrez?.db:gene.

8. Wilschanski M and Durie PR: Patterns of GI disease in adulthood associated with mutations in the CFTR gene. Gut 56: 1153-1163, 2007.

9. Devuyst O, Golstein PE, Sanches MV, et al: Expression of CFTR in human and bovine thyroid epithelium. Am J Physiol 272: C1299-C1308, 1997.

10. Johannesson M: Cancer risk among patients with cystic fibrosis and their first-degree relatives. Int J Cancer 125: 2953-2956 2009.

11. Gabriel SB, Schaffner SF, Nguyen H, et al: The structure of haplotype blocks in the human genome. Science 296: 2225-2229, 2002.

12. Xing M, Westra WH, Tufano RP, et al: BRAF mutation predicts a poorer clinical prognosis for papillary thyroid cancer. J Clin Endocrinol Metab 90: 6373-6379, 2005.

13. Baudin E, Travagli JP, Ropers J, et al: Microcarcinoma of the thyroid gland: the Gustave-Roussy Institute experience. Cancer 83: 553-559, 1998

14. Sampson RJ, Oka H, Key CR, Buncher CR and Iijima S: Metastases from occult thyroid carcinoma. An autopsy study from Hiroshima and Nagasaki, Japan. Cancer 25: 803-811, 1970.

15. Romei C, Ciampi R, Faviana P, et al: BRAFV600E mutation, but not RET/PTC rearrangements, is correlated with a lower expression of both thyroperoxidase and sodium iodide symporter genes in papillary thyroid cancer. Endocr Relat Cancer 15: 511, 2008.

16. Scholte BJ: Thyroid glands from pigs with cystic fibrosis, old issues new ways. Exp Physiol 95: 1131, 2010.

17. Davis PB: Cystic fibrosis since 1938. Am J Respir Crit Care Med 173: 475, 2006.

18. McWilliams RR, Petersen GM, Rabe KG, et al: Cystic fibrosis transmembrane conductance regulator (CFTR) gene mutations and risk for pancreatic adenocarcinoma. Cancer 116: 203-209, 2010.

19. Li Y, Sun Z, Wu Y, et al: Cystic fibrosis transmembrane conductance regulator gene mutation and lung cancer risk. Lung Cancer 70: 14-21 2010.

20. De Andrade Pinto AC, Barbosa CM, Ornellas DS, et al: Thyroid hormones stimulate renal expression of CFTR. Cell Physiol Biochem 20: 83-90, 2007. 